\title{
Dossiê
}

REsumo
A teoria psicanalítica,
ainda que fique entre a
reinvenção e a repetição,
continua parte da formação
analítica e seu ensino é
exigido por várias
instituições psicanaliticas.
A teoria pode evitar que a
transmissão da psicanálise
seja reduzida a transmitir
poderes, mas seu ensino
pode ser assujeitante. O
crivo teórico psicanalítico
aplicado a processos
educativos permite aqui
identificar a formação de
discípulos e, entre aqueles
que ensinam, o desejo nem
tão assumido de futuros
psicanalistas que não
resistam à teoria. Um
ensino compativel com a
psicanálise deveria abdicar
de estratégias de sujeição e
ser permeável aos efeitos do
inconsciente.
Descritores: teoria
psicanalítica; transmissão
da psicanálise; ensino da
psicanálise; formação do
psicanalista

\section{ENTRE O \\ NECESSÁRIO E O IMPOSSÍVEL: O \\ ENSINO DA TEORIA PSICANALÍTICA NA FORMAÇÃO DE PSICANALISTAS}

Paulo Padilla Petry

\section{Introdução}

S)

afouan (1985) afirma que um dos três pontos que seriam admitidos pelos analistas é o de que um psicanalista, independente de sua linha teórica, necessariamente deve passar previamente por uma análise que o habilite, de alguma forma, a analisar outros. Já faz parte da tradição das instituições psicanalíticas a aposta no chamado tripé da formação do analista, composto de análise didática, análise de controle (supervisão, a partir de Lacan) e estudo teórico. Também se pode considerar consenso entre psicanalistas de diferentes orientações teóricas que a formação de novos analistas não é compará-

Doutor em Psicologia do Desenvolvimento pela UFRGS. Professor do Centro Universitário Unilasalle - RS. 
vel à simples aprendizagem de conceitos psicanalíticos ou de uma técnica de trabalho, uma vez que a formação não é redutível ao ensino ou à aprendizagem de conceitos e métodos. O ensino desses conceitos ou do que poderia ser considerada uma técnica psicanalítica nunca foi, portanto, considerado suficiente para a formação de analistas, mas tampouco foi abandonado pelas instituições psicanalíticas. Esse ensino necessário, embora insuficiente, já foi alvo de muitas críticas e ceticismos de psicanalistas, entre eles o próprio Freud. Valabrega (1983), no entanto, chama a atenção para o fato de que é indiscutível que sempre haverá analistas no ensino teórico ou clínico da psicanálise, e que negar a força desse ensino não ilude ninguém. Assim, afirma que o ensino que nega a si mesmo não se torna por isso um ensino melhor.

À semelhança de instituições educacionais como universidades e escolas, as instituições psicanalíticas seguiram propondo currículos de psicanálise com conteúdos a serem ensinados numa determinada ordem. O ensino da teoria psicanalítica dentro ou fora das instituições psicanalíticas tem convivido com as críticas dos psicanalistas, mas também com a relação historicamente complexa entre a psicanálise e o campo da educação. Psicanalistas como Millot (1995), por exemplo, não hesitam em apontar a pouca importância dos métodos de transmissão dos conhecimentos uma vez que o desejo de aprender superaria qualquer método e que, em qualquer ação educativa, o professor teria seu inconsciente agindo sobre o inconsciente dos alunos e seria, portanto, inútil tentar controlar a metodologia usada numa atividade de ensino. Ou seja, as críticas psicanalíticas às atividades de ensino também são pertinentes para a discussão, visto que podem de alguma forma ser aplicadas ao ensino da teoria psicanalítica, seja ele conduzido por psicanalistas ou não.

A impossibilidade de reduzir a psicanálise a uma ciência preditiva e o ofício do psicanalista ao exercício de uma técnica pode, num extremo, levar a minimizar a importância da teoria psicanalítica na formação de novos analistas e na própria prática analítica. Nesse extremo, há uma ênfase marcada sobre o trabalho do analista como dependendo do seu inconsciente e da sua própria análise e, assim, a própria teoria psicanalítica e o seu estudo podem ser considerados prescindíveis. No outro extremo, tem-se a necessidade incontornável da teoria psicanalítica para a formação do analista e para a sua prática, como bem atestam os projetos formativos das instituições e a busca constante da teoria psicanalítica em grupos de estudo, cartéis e outros.

Esses dois extremos e as críticas às atividades educativas podem levar a certo impasse: a teoria e seu ensino são necessários, 
mas ficam num lugar impreciso ou sempre criticável na formação de analistas e na prática analítica. O presente artigo busca discutir teoricamente o que seria, nesse quadro, um lugar possível para o ensino da teoria psicanalítica.

\section{A pesquisa psicanalítica, a construção de teorias psicanalíticas e a transmissibilidade da psicanálise}

O próprio estatuto da psicanálise como ciência e sua transmissibilidade estão em jogo quando se trata de problemas relativos a como se tornar analista. Assim como a pesquisa psicanalítica diferencia-se das pesquisas realizadas em outros campos da ciência, sua transmissão também não pode ser reduzida ao ensino de uma técnica ou de uma teoria. Lacan (1992), no Seminário 17, em resposta a uma estudante, já dizia que a psicanálise não se transmite como qualquer outro saber, mas não porque o psicanalista não tenha nada a saber. As questões referentes à cientificidade da psicanálise e às condições necessárias para uma pesquisa psicanalítica permitem assim abordar a relação entre pesquisa psicanalítica, teoria psicanalítica e transmissão.

Caon (1999) considera que a pesquisa psicanalítica é "pesquisa em intensão, é pesquisa metapsicológica” (p. 57). Ao fazer metapsicologia, o pesquisador psicanalítico não interpreta, mas explica. Pesquisas feitas por psicanalistas só são psicanalíticas se há pesquisa metapsicológica; se o pesquisador é sujeito de pesquisas metapsicológicas, o que "implica refundação da experiência psicanalítica constituída na situação psicanalítica de cura” (p. 58), daí a necessidade de que todo pesquisador psicanalítico passe por uma análise pessoal.

Em um texto anterior a esse, Caon (1994) afirma que a produção metapsicológica de textos é uma alternativa para a pesquisa psicanalítica e para a transmissão da psicanálise. Nesse mesmo escrito, afirma que, ao contrário de textos de filosofia ou das ciências humanas, biológicas e exatas, o texto metapsicológico é inconcluso e marcado por uma falta que sustenta o pesquisador psicanalítico. Caon (1999) fala também da capacidade de fazer acidentalmente descobertas desejáveis; ou seja, essas descobertas acidentais são sempre consideradas determinadas pelo inconsciente do pesquisador, logo, nenhuma delas é inintencional e todas são formações do inconsciente.

A cientificidade da psicanálise através da produção metapsicológica, defendida por Caon, situa a pesquisa psicanalítica como

26 Estilos da Clínica, 2006, Vol. XI, nº 21, 24-47 
necessária e viável sem deixar de considerar a sua especificidade. Ou seja, o pesquisador psicanalítico não pode ignorar que é o sujeito da própria pesquisa, assim como seus achados estão diretamente relacionados ao seu próprio inconsciente. Dör (1993) afirma que, uma vez que a psicanálise parte do princípio de que o sujeito é dividido, nenhuma questão referente ao seu estatuto epistemológico pode ignorar esse princípio. A divisão do sujeito permite compreender em que o campo psicanalítico é refratário aos critérios habituais de cientificidade. Como o campo psicanalítico se sustenta na divisão do sujeito e o discurso da ciência exige uma negação dessa Spaltung, este não pode exprimir adequadamente algo do campo daquele. Ele apresenta então um paradoxo: o discurso psicanalítico fica sujeito a ter que justificar o caráter rigoroso e operatório dos seus enunciados para ambicionar o status das produções científicas num universo de discurso que, de certa forma, atribui o próprio princípio de enunciação científica "à fileira das captações do Ego” (p.19). Assim, de um lado, as construções do discurso psicanalítico tendem a formar um corpo de conhecimento universal, algo que é por excelência um projeto da ciência; de outro lado, o discurso da psicanálise é irredutível ao discurso científico, uma vez que este não deixa de ter nas suas elaborações o imaginário ilusório do sujeito-não-dividido. Se esse paradoxo estende-se para a própria questão da transmissibilidade da psicanálise, qual é o empreendimento epistemológico que é articulado numa teoria psicanalítica?
$\mathrm{Na}$ busca de uma saída para esse impasse, Dör (1993) cita as idéias de Roustang para criticá-las em seguida. Parte desse autor, segundo Dör, a seguinte oposição: ou a teoria psicanalítica independe da experiência e assim é inverificável ou ela baseia-se na experiência, mas apenas a descreve ou narra-a com uma nova terminologia. Segundo Dör, para resolver esse dilema, Roustang introduz a noção de "monofema", segundo a qual boa parte do discurso do analisante está radicalmente fora de qualquer possibilidade de generalização teórica, seja por insuficiência da teoria, seja pelo caráter totalmente particular do dizer do analisante.

Para Dör (1993), no entanto, como a teoria é produto do trabalho das fantasias e desejos do teorizante na sua própria análise, ela pode funcionar para outro analista como um sintoma ou um sistema no qual se está preso. Por outro lado, sem uma tentativa como a de Freud, de elaborar uma teoria geral, não haveria psicanálise, pois sua transmissão sem um corpo teórico poderia ficar reduzida a consensos iniciáticos, e o efeito da análise seria reduzido ao poder pessoal ou aos dons do analista. Sem uma tentativa de teorização, a transmissão da psicanálise poderia equivaler a poderes e dons que são transmitidos de um indivíduo a outro pela comunicação de algum segredo. Como o problema da transmissibilidade não escapa da dimensão da transferência, o universal da psicanálise está fundado na indeterminação. Ela necessita da irracionalidade da transferência para que sua cientificidade seja pretendida e, ao 
mesmo tempo, a crença na sua cientificidade efetiva leva a esquecer que a transferência é sua origem. Nenhuma racionalidade pode respeitar o dizer do inconsciente, mas ele não pode ser reconhecido nem formulado como hipótese fora de uma tentativa de cientificidade. Além de a psicanálise estar condenada a situarse nessa extremidade, ela estaria também "condenada à invenção" (Roustang, 1976, citado por Dör, 1993, p. 118).

Dör (1993) critica Roustang dizendo que nada intrínseco à prática analítica condenaria o analista à invenção ou a ignorar a teoria preexistente. Usar uma teoria preexistente encontrando nela suas próprias referências não condenaria necessariamente alguém a uma posição de aluno subjugado a um Mestre. Se não há teoria a não ser aquela destinada a ser desconstruída, "a prática analítica toma a feição inevitável de um ministério" (Dör, 1993, p.124) e a ética de tal práxis só pode apoiar-se numa "crença incondicional nas virtudes filantrópicas do prático" (Dör, 1993, p. 124). Finalmente, Dör critica Roustang por entender que a "condenação à invenção" cai numa dupla armadilha especulativa: o círculo hermenêutico e o solipsismo. Uma vez que a invenção de cada analista seria uma intervenção hermenêutica, o analista deveria ter uma compreensão exaustiva de si mesmo para poder fundamentar a sua interpretação. Essa autocompreensão radical remete, por sua vez, ao solipsismo epistemológico que, segundo o autor, é uma forma de solipsismo considerada apropriada ao campo psicanalítico, por

28 Estilos da Clínica, 2006, Vol. XI, nº 21, 24-47 
aliar certo ceticismo à ingenuidade do agnosticismo. Crítico do solipsismo, Dör afirma que um psicanalista não poderia defender o que sua prática lhe ensina se tiver de adotar uma atitude solipsista. Mesmo que possa ser "um aditivo muito precioso em uma certa perspectiva de conduta do tratamento" (Dör, 1993, p. 128), essa atitude solipsista ratificaria a "impossibilidade teórica de administrar a paradoxalidade que levanta a validação do discurso analítico" (Dör, 1993, p. 128). Como esse princípio dependeria da ficção, haveria o risco de caucionar incondicionalmente pseudoteorias que seriam discriminadas por aderirem ou não à eficácia de uma prática. Por não ser necessária uma legitimação da invenção a não ser para o próprio inventor na sua prática, haveria um espaço indefinido de especulações e ecletismo.

Em relação a Caon, Dör parece preocupar-se mais com o quanto as teorias poderiam legitimar-se apenas como produção do inconsciente do pesquisador. Ainda que ambos reconheçam a limitação que a transferência oferece para tentativas de sistematizações científicas, Caon parece apostar mais numa produção metapsicológica cuja validação independa de outros psicanalistas, enquanto Dör parece mais preocupado com a inserção dos frutos da pesquisa psicanalítica no conjunto de outras teorias e na comunidade dos pesquisadores psicanalíticos.

Como Dör (1993), Cottet (1989) também critica aqueles que pensam ser a teoria psicanalítica incompatível com a transferência ou uma defesa contra ela. $\mathrm{O}$ autor argumenta que existe uma epistemologia freudiana, segundo a qual os efeitos de verdade produzidos pela interpretação são homogêneos à teoria. Sustenta que o que importa numa interpretação ou numa construção não é chegar à verdade material e, sim, produzir uma certeza. Cita Freud, no entanto, para lembrar que mesmo ele estabelecia uma diferença entre verdade material e histórica, admitindo, por exemplo, várias versões da cena primitiva. O efeito de verdade da construção importava mais para Freud do que uma concordância com a realidade, visto que se tratava de preencher uma lacuna simbólica que só uma palavra pode dar.

Birman (1994) também parte do discurso freudiano para tentar especificar o que seria a leitura freudiana da pesquisa psicanalítica e sustenta que, nele, o fundamento da ciência é a observação e não a construção de conceitos para uma teoria especulativa. Para o autor, a oposição entre a psicanálise e a filosofia em Freud impõe uma indagação sobre o estatuto da metapsicologia, ou seja, quais as diferenças e semelhanças entre a psicanálise, a filosofia e a psicologia? A metapsicologia não se identifica com a psicologia porque a psicanálise, sem ser uma "psicologia das faculdades e do eu" (p. 19) 
nem estando baseada na introspecção, funda-se na pesquisa do inconsciente.

Birman chama a atenção para o fato de que, no intuito de construir uma outra modalidade de psicologia baseada no inconsciente e nas pulsões, Freud não se baseou nem nos cânones de cientificidade da época nem na psicologia introspectiva. Ao contrário de Caon (1999), Birman (1994) sustenta que o discurso freudiano de fato realizava "operações de interpretação, baseadas na escuta dos analisantes, de onde construía as suas hipóteses metapsicológicas sobre o psiquismo" (p. 19). O estatuto epistemológico desse saber da interpretação sobrepunha-se muitas vezes à arte e à filosofia, não havendo reconhecimento de um rigor científico. Birman (1991) já havia afirmado que, mesmo que o contexto histórico da constituição da psicanálise tivesse induzido à formalização de um saber conforme a um ideal científico, "esse processo revalorizou o pressuposto epistemológico que conferia pregnância à categoria de sentido, tornada principal face à categoria de explicação no estudo da experiência da loucura" (p. 71). Nesse mesmo texto, o autor diferencia a interpretação freudiana de outros métodos de interpretação do senso comum: ela "estabelece uma relação fundante, dialética, entre sujeito e sentido" (p. 77). Ou seja, o sujeito necessariamente remete ao sentido e vice-versa; a interpretação psicanalítica torna-se, assim, uma leitura rigorosa cujo objetivo é restaurar o sentido singular da história de uma subjetividade. Birman (1994) conclui que, apesar da preten- são de Freud, não foi possível adequar o discurso psicanalítico às exigências da cientificidade. As operações metodológicas da psicanálise aproximam-se dos saberes da história e da linguagem, o que Roudinesco (2000) confirma ao dizer que a psicanálise parece ser uma ciência do homem e não da natureza, ainda que Freud possa ter tentado integrá-la às ciências da natureza.

Sobre a necessidade de produzir teoria a partir da indeterminação da transferência, já mencionada por Dör (1993), Birman (1996) salienta que a dupla referência do discurso freudiano - uma referência transferencial e uma referência ao saber marca a especificidade da psicanálise em relação a outros campos de conhecimento. Para o autor, após o término da transferência na experiência psicanalítica, os analistas retomam o que foi neles depositado como transferência de trabalho e investem na teorização da psicanálise.

Pode-se concluir que, para assegurar sua transmissão e sua própria existência, a psicanálise necessita, de alguma forma, de uma produção teórica generalizável que não seja ignorada pelos psicanalistas, como também precisa considerar a irracionalidade da transferência e a Spaltung do próprio pesquisador que, como afirma Caon (1999), é também o sujeito da pesquisa que conduz. Como afirma Dör (1993), a transmissão da psicanálise sem um corpo teórico ficaria reduzida a consensos iniciáticos, e o efeito da psicanálise, a poderes pessoais do analista. Porém, de fato, a psicanálise depende da irracionalidade da transferência e, conseqüen- 
temente, do analista como sujeito e não como um mero aplicador ou seguidor de técnicas. Assim, não pode, por um lado abdicar totalmente de alguma teorização com estatuto de ciência nem, por outro lado, ignorar a transferência.

Birman e Caon aproximam-se quanto à suposição de que a pesquisa psicanalítica deverá sempre estar baseada na clínica psicanalítica, e de que não faz sentido opor uma psicanálise dita pura a outra dita aplicada, pois a única pesquisa psicanalítica seria aquela que ocorre sobre a experiência analítica baseada na transferência, ou seja, sobre a clínica psicanalítica. Enquanto Caon (1999) defende a produção metapsicológica freudiana como tentativa de explicar o que ocorre na clínica psicanalítica, Birman (1994) sustenta que o estatuto epistemológico das operações de interpretação realizadas por Freud aproxima-se mais da arte e da filosofia que da ciência. De qualquer forma, os dois autores, assim como Dör (1993), assumem a necessidade de unir clínica e teoria, sendo Caon um grande defensor da pesquisa psicanalítica como uma alternativa para a formação de analistas que não sejam apenas reprodutores de teorias alheias. Assim, por um lado, a simples repetição de teses psicanalíticas não provaria a transmissão da psicanálise; por outro lado, a obrigação de tudo inventar sem se referir a teorias psicanalíticas pré-existentes inviabilizaria essa transmissão. A dualidade entre tudo inventar e tudo reproduzir estaria relacionada ao lugar da teoria psicanalítica na transmissão da psicanálise?

\section{O ensino da teoria psicanalítica}

\section{Freud e o ensino da teoria psicanalítica}

Freud (1913/1969a) afirma que a responsabilidade de um educador pode superar a de um médico, visto que este lida com estruturas psíquicas que já se tornaram rígidas. A distinção estabelecida por Freud entre a plasticidade do pensamento infantil e a rigidez do pensamento adulto parece refletir-se no seu ceticismo a respeito da possibilidade de aprender sobre a técnica da psicanálise sem passar por uma análise. Ele fica claro em "A questão da análise leiga" (1926/1969b), quando Freud afirma que os representantes de várias ciências deveriam "aprender a análise da única maneira possível - submetendo-se eles próprios a uma análise" (p. 281). No texto sobre as resistências à psicanálise, Freud (1925/1969c) conclui que é difícil ter um julgamento isento em relação à psicanálise sem ter passado por uma análise ou sem tê-la praticado: o que é paradoxal, uma vez que dificilmente se poderia considerar isento alguém que resolva ser analista ou submeter-se a uma análise. A atenção de Freud em relação à atitude de quem recebia o ensino teórico psicanalítico era evidente.

"Quando ministramos aos nossos alunos instrução teórica em psicanálise, podemos ver quão pouca impressão lhe estamos causando, para começar. Eles absorvem as teorias da análise tão friamente quanto outras 
abstrações com as quais são alimentados. Poucos deles talvez desejam ficar convencidos, mas não há qualquer vestígio que estejam." (Freud, 1926/1969b, p. 226).

Kupfer (2001), indo além das posições de Freud sobre a educação, aborda a sua relação com seus mestres e alunos. Assim como Freud dizia ter buscado a Neuropatologia, disciplina na qual pensava que deveria ser seu próprio mestre, também fazia movimentos de apego apaixonado a mestres que depois abandonava por divergências teóricas. Como essas relações de fato repetiam a relação com seu pai, apenas após superá-la, através da correspondência com Fliess, Freud teria podido assumir o lugar de mestre e destituir seus mestres do lugar de pai. Ao mesmo tempo em que conseguia aprender com seus pacientes, Freud rompia com os discípulos que, introduzindo idéias novas, pareciam alterar ou desvirtuar a psicanálise. O fascínio que Freud exercia sobre eles levava tanto a rompimentos definitivos e suicídios como à existência de defensores apaixonados. Para a autora, Freud, como mestre, ainda sofreu pela relação com seu pai, mas dessa vez numa posição diferente.

Como Kupfer (2001), Ferreira (1998) propõe-se a pensar sobre o ensino de Freud. Considera esse ensino um ato no sentido psicanalítico do termo, "aquele que faz com que o sujeito possa se liberar dos efeitos do significante e do saber do Outro" (p. 109). Ferreira afirma que o "estilo oral" de Freud nas suas conferências era simples, fluente, imaginativo e repleto de histórias e metáforas. Reunia a platéia próxima a si e falava de forma coloquial. Citando Jones, a autora observa que Freud preferia deixar a palestra a cargo do seu inconsciente e não usava recursos de oratória; ou seja, colocava o sujeito em relação ao saber, mas também em relação aos efeitos de verdade. Por isso, Freud pedia que suspendessem o julgamento; por considerar as resistências dos ouvintes e leitores. "Freud muito cedo entendeu que o ensino da psicanálise - e talvez se possa estender isso quanto ao ensino de um modo geral - não seria uma mera transmissão de saber, ou um gesto de repassar conhecimento, ou ainda um movimento onde um aprende o que o outro ensina. Em vários momentos de seu ensino, ele traz a oposição entre saber e verdade, situando esta última no lugar daquilo que traz desprazer ao sujeito, daquilo que causa horror, daquilo que o sujeito nada quer saber. A disjunção entre saber e verdade faz com que Freud conclua que o saber não opera nenhuma mudança no sujeito." (Ferreira, 1998, p. 135).

Para Ferreira, o ensino de Freud tinha a marca de não se deixar levar exclusivamente por uma posição de mestria, não apenas oferecer saber, pois compreendia que este seria produzido pelo sujei- 
to na sua relação com sua própria verdade. O fascínio de Freud pelo ensino de Charcot estaria relacionado ao fato de ele trazer para suas aulas casos completamente desconhecidos, arriscando-se a errar ou a não conseguir, por exemplo, chegar a um diagnóstico. Assim, estreitava a distância entre professor e aluno. Citando um comentário de Freud sobre mestres como Charcot e Breuer, a autora conclui que Freud entendia que a transmissão não era de um conhecimento e sim de algo que faz o sujeito produzir um saber pela forma como o ato de ensinar é sustentado.

"Freud diz ter ouvido algo dessas pessoas que não pôde, na época, compreender, mas que tinha ficado presente nele durante anos e que despertou sob a forma de uma descoberta original. Acrescenta ainda que aqueles mestres não reconheceram nas idéias dele as suas próprias. Eles transmitiram algo que não sabiam que sabiam." (Ferreira, 1998, p. 138).

No final do seu artigo, assume que o saber de Freud sobre a transferência e sobre as disposições estruturais que impedem o sujeito de se relacionar com determinados conteúdos tornaria o seu ensino um ato analítico. E conclui afirmando que Freud, por ser autor do que ensinava, não reproduzia saber. Estava em permanente pesquisa deixando questões em aberto para que seus ouvintes ou alunos se interrogassem e se implicassem constituindo saberes próprios. A autora considera que, se há uma pedagogia em Freud, ela se mantém a partir da consideração do trabalho do inconsciente.

Confrontando as posições de Kupfer (2001) e Ferreira (1998), parece claro que a última não levou em consideração a relação de Freud com seus discípulos, tendo baseado suas conclusões mais sobre o conhecimento psicanalítico de Freud do que sobre o que de fato se passava a partir do seu ensino. Assim, assumiu que o Freud psicanalista conseguia fazer do seu ensino um ato analítico. $\mathrm{O}$ que chama de estilo oral de Freud e suas referências às resistências da platéia não podia ser confundido com um ensino que de fato renunciasse à mestria, coisa que Freud não fazia. Que Freud falasse como analisante, ou seja, que deixasse o imprevisível do inconsciente aparecer no seu discurso e mesmo nos seus textos novamente não parece suficiente para afirmar que seu ensino fosse um ato analítico. Igualmente, a idéia psicanalítica segundo a qual um professor ensina mais do que pensa ou pretende ensinar e de que um aluno não se apropria exatamente de tudo que lhe foi ensinado; nada disso é suficiente para concluir que alguém que saiba disso, como Freud sabia, consiga ensinar de outra forma. O fascínio de Freud pelo ensino de Charcot assim como seu estilo coloquial de dialogar com um suposto interlocutor podem, sem dúvida, estar 

"conselheiro pedagógico" (p. 36) que ajuda o candidato na sua formação.

$\mathrm{O}$ autor menciona também a preocupação com a simultaneidade de dois processos: a análise didática e a participação nos seminários teóricos. Seria prática comum em diversas instituições não permitir o estudo da teoria psicanalítica no início da análise didática. Nota-se, assim, que o estudo teórico ganha importância, ainda que negativa. Se há que se controlar o que é estudado, definir a ordem dos conteúdos e não permitir a "intrusão dos conhecimentos psicanalíticos na análise pessoal” (p. 35), pergunta-se: isso se deve ao fato de o estudo teórico atrapalhar ou inviabilizar a formação de um analista? Como uma nem tão longínqua decorrência da preocupação freudiana, algumas instituições parecem querer garantir através da análise didática a atitude correta em relação à teoria psicanalítica que será apresentada posteriormente. Infelizmente, Lebovici não aprofunda nem esse nem outro ponto importante que menciona no início: reticências a falar de educação ou ensino, uma vez que os candidatos não são crianças. Menciona, mais adiante, uma preocupação que pode estar relacionada a essas reticências. Segundo o autor, assim como alguns pensam que grupos grandes não conseguem resolver bem alguns problemas pela presença de figuras carismáticas, ele duvida de que grupos pequenos estejam em situação mais favorável; a formação começa em torno de um "personagem central" (p. 41) que pode vir a ter uma influência forte demais no seu desenvolvimento. $\mathrm{O}$ autor parece assim estar tratando da oscilação entre dois pólos: a necessidade do controle e do ensino dos mestres carismáticos e o receio de tratar os candidatos como crianças, ao temer que uma influência excessiva desses mestres prejudique a formação de analistas. De qualquer forma, aparenta lidar com uma relação ambígua com o conhecimento da teoria psicanalítica, uma vez que o tempo e a ordem parecem fazer muita diferença.

Em Solnit (1982) encontra-se uma defesa do ensino da teoria psicanalítica somente nas instituições. $\mathrm{O}$ autor fala em proteção do candidato, quando se refere a um possível ensino inadequado ou improdutivo que encontraria fora da instituição; contudo, usa também o mesmo termo para falar da proteção do professor e do aluno "contra uma resistência não reconhecida do analista formador em relação ao analisante, à análise e ao ensino da análise" (p. 47). Defende, no entanto, grupos de estudo voluntários depois de o candidato ter sido reconhecido como analista, e para isso lembra que as palestras do primeiro instituto psicanalítico (Berlim) eram abertas ao público.

$\mathrm{O}$ autor menciona também algumas recomendações de Anna Freud em relação ao ensino, entre elas: que a teoria seja introduzida no seu contexto histórico e elaborada por uma série de conceitos; que o ambiente permita uma "aprendizagem ativa” (p. 55) para evitar uma abundância de ensino com uma instrução insuficiente e que haja observação fora de análise de pacientes psicóticos em hospitais psiquiátricos, interação entre mãe e criança e até mesmo de 
fenômenos psicossomáticos. Na conclusão, Solnit (1982) refere-se a um célebre artigo de Bernfeld dirigido ao Instituto e à Sociedade Psicanalítica de São Francisco em 1953. Retoma, em especial, as críticas de Bernfeld ao sistema de ensino adotado nas instituições psicanalíticas ligadas à IPA, em que o sistema é descrito como pré-psicanalítico, centrado no professor e dominado por questões administrativas e políticas.

"Mencionar esses fatos não deve ser considerado uma censura. Nossos programas de formação são garantidos por analistas muito ocupados - a maior parte deles, médicos. Eles permitem raramente uma experimentação e caímos em métodos de ensino do passado. O modelo de escola centrado no professor, e pré-psicanalítico, vem facilmente à mente, enquanto uma escola centrada no estudante, e psicanalítica, exige uma criação e uma experimentação, e encontra então resistências; essa escola deve, entretanto, ser concebida e conduzida contra as tendências naturais e arcaicas de nosso ensino." (Bernfeld, 1962 citado por Solnit, 1982, p. 59).

Solnit (1982) praticamente nada elabora sobre as citações que faz, mas se pode supor que intencionalmente escolheu críticas aos métodos de ensino tradicionais adotados nas instituições psicanalíticas. Confrontando essas críticas com sua defesa do ensino dentro, e não fora das instituições psicanalíticas, parece que o autor tentou manter-se fiel ao controle das instituições, sem deixar de criticar seus métodos de ensino. Chama a atenção que tanto Bernfeld como Anna
Freud tenham proposto mudanças que já foram exaustivamente debatidas no campo da educação. Assim como em Lebovici (1982), nota-se em Solnit (1982) a mesma oscilação entre um aluno candidato que precisa ser protegido das más influências teóricas e outro que precisa ser mais ativo na sua formação. Ao contrário de Lebovici (1982), Solnit (1982) parece preocupado com os métodos de ensino. Qual seria exatamente o prejuízo produzido por tais métodos? $\mathrm{Na}$ citação de Bernfeld, este fala em deformação de características valiosas da psicanálise e retardo de seu desenvolvimento enquanto ciência e instrumento.

Entre os lacanianos, também se pode encontrar posições que parecem resultar de contradições difíceis de resolver. Aflalo (1992), tratando das funções de uma escola de psicanálise e defendendo a sua existência, afirma que a psicanálise não é integralmente transmissível; nesse caso, seu "corpus de saber não basta para definir o psicanalista, e de outra parte o saber estabelecido da psicanálise não é como tal diretamente operativo sobre o sintoma" (p. 22). Uma vez que a análise prévia do analista é indispensável, a autora chega ao seguinte paradoxo: a clínica do sintoma pode ser ensinada a partir de conceitos, mas, embora necessários, não são suficientes, e o que opera é o desejo do analista, fruto da psicanálise em intensão. Se o tratamento é necessário para produzir um analista, Aflalo questiona se também é suficiente, e levanta três objeções:

(a) o tratamento não transmite os conceitos que organizam a expe- 
riência - logo, o futuro analista ignoraria o que lhe faz a força, o que está no campo de sua competência;

(b) a análise seria reduzida a um rito iniciático e cada analista teria uma prática decorrente de sua experiência como paciente como a psicanálise não pode ser reduzida à técnica de uma prática, a Escola seria fundamental para assegurar uma prática conforme o ensino de Lacan e

(c) nem todos os finais de um tratamento seriam compatíveis com a produção de um analista.

Sem dúvida, a última objeção de Aflalo pode ser questionada a partir de Lacan, pois uma análise só pode ser dita didática a posteriori. Se, ao final do tratamento, não há um analista, a condição colocada como necessária pela própria autora não foi satisfeita. Apesar de ela não considerar a análise como condição necessária e suficiente para a produção de analistas e defender a existência de uma Escola cuja função seria assegurar a transmissão da psicanálise e não apenas ensiná-la, não faz qualquer referência a como deveria ser esse ensino. Ora, parece que a autora estava dividida entre precisar defender a instituição psicanalítica como instância de ensino e autorização de novos analistas (decidiria se a análise didática produziu de fato um analista) e considerar como operativo o desejo do analista como produto de sua análise.

Quinet (1992), por outro lado, avança na direção de indagar o que o analista deve saber, mas cita Lacan para dizer que ele deve ignorar o que sabe para poder reinventar a psicanálise cada vez. Salienta que esse não-saber como produto é diferente de uma ignorância. Há então a necessidade de uma acumulação de saber na formação do analista, e novamente retoma Lacan, para dizer que o psicanalista deve aprender os métodos do lingüista, do historiador e do matemático. Conclui que, ao percorrer um programa de formação, o analista chegaria à "ignorância necessária a sua formação" (p. 145).

Assim como Aflalo (1992), Quinet sustenta que o analista deve saber o que fundamenta a experiência analítica e que, se a teoria psicanalítica for vacilante para ele, a ética e o ato analítico falharão. No ensino do saber textual, "cabe ao ensinante colocar a obra de Freud e o ensino de Lacan no lugar de significantes-mestres com o estatuto de enigmas a serem decifrados: prática do comentário, da exegese, da interpretação, do questionamento, da seriação etc." (Quinet, 1992, p. 145).

Quinet menciona a impossibilidade de o analista furtar-se a um estilo "que diz respeito à verdade do sujeito manifesta no retorno do recalcado submetido aos desfiladeiros do significante" (1992, p. 146). Tanto o estilo de Freud como o de Lacan implicava 
a verdade do inconsciente, que transparecia no recurso à poesia e na qualidade de escritor. O autor, no entanto, cita também a via do matema, introduzida por Lacan. O matema seria científico e passível de ser ensinado. Sem dúvida, o autor consegue estabelecer uma oposição interessante entre a via do matema e a via do estilo, mas parece relutante e contraditório em relação ao saber, chegando ao extremo de propor um acúmulo de saber que produziria a ignorância necessária. Parece que novamente se está diante da dificuldade de encontrar um lugar para a teoria psicanalítica na formação e no trabalho do analista.

Em relação ao ensino dessa teoria, não se deveria, a partir de Lacan, esperar muito dele; é o que se pode constatar na sua intervenção no encerramento do congresso da Escola Freudiana de Paris de abril de 1970. Nela, Lacan (2003) estabelece uma oposição entre ensino e saber, o primeiro colocando uma barreira para o segundo e não havendo uma relação óbvia entre os dois. Lacan questiona se o ensino criaria obstáculos para que o analista saiba o que diz. Sendo assim, a idéia de que o instinto desorientaria seria decorrência da fabricação do ensino, e o discurso psicanalítico não se sustentaria se o saber necessitasse da intermediação do ensino. Lacan (2003) conclui sua alocução dizendo que o discurso psicanalítico, ao se oferecer ao ensino, leva o psicanalista a uma posição de psicanalisante, ou seja, a não produzir nada que se possa dominar, a não ser como sintoma.

\section{3. $O$ ensino da teoria psicanalítica entre o assujeitamento produtor de discípulos e um ensino compatível com a psicanálise}

Melman (n.d.) atribui a Lacan a idéia de que o psicanalista é um mestre que não tem discípulo, definindo discípulo como alguém que organiza sua compreensão do mundo a partir do saber do seu mestre; saber que usa para curar a angústia que poderia abrir a dimensão do Outro. Faz isso à custa de uma mortificação, ou seja, o discípulo perfeito estaria morto como sujeito. Os discípulos, no entanto, são uma catástrofe, são perigosos, porque acabam transformando o que os mestres dizem em algo que deve se revelar como uma realização perfeita. Por mais que o discurso do mestre busque uma liberdade do discípulo ou até mesmo reconheça um não saber, ele só terá valor para o discípulo como algo que permita eliminar a angústia da falta. Ele questiona então se os psicanalistas também são discípulos, se poderiam ser diferentes, e não quererem que o saber de seu mestre seja total? Para ele, a psicanálise propõe uma ruptura considerável, e mesmo quem ten-

38 Estilos da Clínica, 2006, Vol. XI, nº 21, 24-47 
te não reconhecer no Outro algo que possa servir de mestre, estará sempre sob o efeito de mestria produzido pelo significante; ou seja, outras formas de alienação ainda mais pesadas podem surgir. De fato, Melman (n.d.) não chega a tratar dos analistas no seu ensino, limitando-se ao trabalho do analista na clínica psicanalítica. Assim, pode afirmar que uma análise que chegasse a seu fim de cura ensinaria tudo que haveria para aprender e, assim, toda análise seria didática. O analista como mestre que conduz uma análise é original; ao invés de interditar o saber, conduz o analisante na sua direção, e é mestre porque, de alguma forma, pressiona, convida o analisante a ir nessa direção e, se não o fizer, não há motivo para que o analisante o faça. No entanto, como mestre na condução de uma análise, o analista visa a sua própria perda. Parece claro que o analista não deve produzir discípulos entre seus pacientes, mas Melman (n.d.) evita tratar da formação de discípulos nas instituições psicanalíticas.

De acordo com Dör (1994), é possível um ensino da teoria psicanalítica compatível com a psicanálise. Ele inicia seu livro Clinique psychanalytique afirmando que todo ensino assume mais ou menos a forma do discurso universitário, e que introduzir a referência da clínica psicanalítica em tal discurso constitui um desafio bastante difamado por clínicos professores e seus alunos. Se, por um lado, não se ensina a psicanálise, visto que ela apenas se transmite e nenhuma instituição que se proponha a ensinar a psicanálise busque compensar de alguma forma a falta do divã; por 
outro lado, tal instituição deve provar que pode desenvolver um ensino compatível com as vicissitudes da transmissão. Dör (1994) segue especificando que tal fato não é característico apenas das instituições de tipo universitário, mas também do programa de formação das instituições psicanalíticas.

Que a instituição psicanalítica busque integrar o ensino a um projeto de formação do analista e que a instituição universitária busque assujeitar o aluno a um gradus medido por um controle não justifica a alegação comum de que um ensino que tome as vias de um discurso universitário prejudique a transmissão da psicanálise. Dör afirma que a oposição entre transmissão e ensino encontra-se grandemente desviada, e que ela existiria, de fato, entre "as virtudes didáticas de um certo perfil de discurso estruturalmente presente nas instituições analíticas" (p.15) e o modo de ensino nas instituições universitárias. Sendo assim, aponta que alguns pensam que é possível promover um ensino sobre o inconsciente. Dör cita Laplanche: “... é uma maneira analítica de falar de análise, tal que o discurso, por ele mesmo, tem um impacto analítico (...) O que eu quero fazer entender, é que existe uma comunicação analítica possível porque ela se funda sobre a comunicação virtual de cada um a seu próprio inconsciente." (Laplanche, 1975, citado por Dör, 1994, p. 15).

Para Dör, Laplanche considera possível uma enunciação propícia ao ensino da psicanálise ainda que sob a tutela do discurso universitário. Cita também Fedida, quando diz que La- can surgiu como um modelo de ensino da psicanálise completamente diferente do ensino universitário. Dör lembra que Lacan afirmava que a psicanálise não se ensina; contudo, isso não impediu que seu ensino fosse instituído e representado no quadro do dispositivo universitário, concordando assim com a crítica de Valabrega (1983).

O texto de Laplanche referido por Dör (1994) é o editorial do primeiro número da revista Psychanalyse à l'Université, e nele Laplanche (1975) defende a possibilidade de se ensinar a psicanálise na universidade e critica as instituições psicanalíticas pelas suas hierarquias, cursos e estatutos. Defende que o ensino da psicanálise seja sempre transparente, ou seja, que haja uma "permeabilidade aos efeitos do inconsciente" (p. 9). Admite que essa é uma exigência difícil e critica o ilusionismo e as manobras retóricas assim como a suposta abertura e liberdade de lugares que, na verdade, trazem conceitos novos mais pesados e tirânicos que os antigos, pois são conceitos difíceis de determinar e vagos.

Dör (1994) propõe que se aceite que haja uma maneira analítica de falar da psicanálise e que isso possa ter um impacto analítico. Segundo ele, essa idéia pode justificar o esforço empregado no quadro de um ensino para comunicar qualquer coisa da clínica psicanalítica. Como o que sustenta uma relação analítica é justamente a transferência, para Dör, se é possível um ensino da psicanálise, é através da transferência de trabalho, e qualquer instituição que pretenda ensinar a psicanálise fica em contradição com ela se estiver fora dessa di- 
mensão. Mais ainda, a instituição deve também prover uma "acolhida favorável aos efeitos imprevisíveis que ela causa" (p. 19). Dör (1994) afirma que todo ensino implica um assujeitamento, ou seja, colocar o sujeito aluno na dependência do sujeito professor, o que costuma ser neutralizado em outros ensinos pela suposta independência entre sujeito e objeto. $\mathrm{O}$ autor considera qualquer estratégia transferencial de sujeição de parte da instituição incompatível com uma transferência de trabalho eficaz compatível com o ensino da psicanálise, e pensa que quem ensina a teoria psicanalítica pode apenas renovar perpetuamente uma aposta: "conduzir o aluno a identificar no ensino não apenas o que pôde fazer eco na sua própria subjetividade, mas ainda o que pôde 'trabalhá-la' com o fim único de leválo a pressentir as intuições analíticas suscetíveis de regular a aptidão de sua confrontação à clínica." (p. 21).

Dör conclui que o ensino da psicanálise não pode se furtar a um estilo, o que é diferente de critérios metodológicos. A escolha metodológica depende de uma adesão imaginária a um aspecto mais evocativo ou formal do saber teórico, e revela uma preferência, visto que o saber teórico comporta ambos os aspectos. "O estilo, por outro lado, como ele é, sobretudo, ressurgimento do acesso pessoal do ensinante à teoria pela dimensão da transferência inerente à sua análise, estigmatiza inevitavelmente no 'après-coup', a menção de sua resistência própria à verdade do saber inconsciente." (Dör, 1994, p. 31).

Dör (1994) e Laplanche (1975) parecem concordar quanto à neces- 
sidade de uma transparência da parte de quem se propõe a falar sobre a psicanálise. Qualquer um que se proponha a um ensino da teoria psicanalítica em instituições psicanalíticas ou universidades deveria abdicar de qualquer estratégia de sujeição dos alunos ao seu saber, expor o seu acesso pessoal à psicanálise com suas resistências e apostar no estabelecimento de uma transferência de trabalho. Quinet (1992) segue uma linha de pensamento semelhante. Quando trata da transmissão da psicanálise, esclarece que o ato psicanalítico não é transmissível, uma vez que é mais vinculado à ética do que à técnica, é impossível generalizá-lo. O desejo do analista também não é transmissível e, portanto, não há algo que passe de analista para analisante como num ritual de iniciação. Quinet afirma que o ensino da psicanálise deve ser pensado pela posição do analisante: "quem ensina é o sujeito dividido" (p. 144), ou seja, aquele que ensina "é um trabalhador cuja construção do saber é ordenada por aquilo que não sabe, mas interroga" (p. 144). Assim, no ensino da psicanálise, o que estaria em jogo seria a transferência de trabalho e não o trabalho de transferência.

Por mais que a psicanálise possa avançar na via do matema, parece consenso entre alguns psicanalistas lacanianos que seu ensino nunca poderá ser como o ensino de outras disciplinas em que há a suposição de uma independência entre sujeito e objeto. Para o professor importa apenas tornar o objeto, de alguma forma conhecido por ele, inteligível para o aluno. Para que seja possível falar da psicanálise, é impossível, portan- to, que não esteja em jogo a subjetividade de quem fala. O conceito de estilo aparece em Dör (1994) e Quinet (1992) para tentar explicar o que há do inconsciente do analista no seu trabalho e também no seu dizer sobre a psicanálise. Segundo Chemama e Vandermersch (1998), assim como se fala do estilo de um artista, também se poderia falar do estilo de um psicanalista. "O ensino escrito ou oral de um psicanalista faz parte de um laço transferencial que existe nas curas, e particularmente naquelas que terão conduzido alguns a se tornarem psicanalistas." (p. 408).

\section{Onde situar o ensino da teoria psicanalítica?}

Para pensar sobre o ensino da teoria psicanalítica, não se pode ignorar que o lugar da própria teoria está longe de ser trivial. Assim como se fala em assujeitamento a um mestre que ensina a teoria, também se diz que um psicanalista pode estar assujeitado à teoria de outro. Todavia, assim como se pode considerar que a produção de teorias evita que a transmissão da psicanálise se limite a uma transmissão de poderes (Dör, 1993), o ensino e o estudo da teoria psicanalítica também podem ser considerados balizas necessárias para que a prática psicanalítica não seja apenas fruto da própria análise. Como Birman (1996) afirma, a dupla referência do discurso freudiano à transferência e ao saber marca a especificidade da psicanálise em relação a outros campos de conhecimento. 
Ainda assim, essa dupla referência pode aparecer às vezes como ambigüidades teóricas em torno do lugar da teoria psicanalítica, como acontece quando se considera que ela não pode ser abandonada, mas pode ser considerada o sintoma de outro psicanalista (Dör, 1993); ou que deve ser estudada e ensinada, mas tem que ser ignorada (Quinet, 1992); e, ainda, deve ser aceita, mas não pode ser contrastada com teorias que a contestem de alguma forma. Não é possível, neste trabalho, determinar como tais ambigüidades retornam na formação de futuros analistas, mas seria interessante pensar como elas podem estar relacionadas à repetição autoritária e assujeitante de verdades incontestáveis e à formação de discípulos como aqueles a que Melman (n.d.) se refere.

É preciso levar também em conta a relação desses conflitos em torno do lugar da teoria psicanalítica e a dificuldade de tolerar as diferenças teóricas, colocando-as fora do campo teórico psicanalítico. Como as diferenças teóricas se relacionariam com a dificuldade de interlocução teórica de alguns psicanalistas com campos possivelmente concorrentes como a psicologia ou as neurociências? Finalmente, o quanto a falta de discussão teórica entre psicanalistas divergentes está relacionada à exigência de futuros psicanalistas plenamente dispostos a aceitar a teoria psicanalítica que lhes será ensinada?

A preocupação, presente em alguns textos, com as conseqüências do estudo de teorias psicanalíticas consideradas inadequadas e com a devi- 
da aceitação do ensino teórico pelos futuros psicanalistas parece mostrar que esse ensino está longe de ser indiferente. $\mathrm{O}$ receio em relação ao ensino de outras teorias também aponta para uma sonhada possibilidade de aceitação integral sem questionamentos, já que ela acolheria até as teorias divergentes. Se a atitude crítica do futuro psicanalista frente à teoria pode ser tomada por alguns como resistência, por falta da própria análise, a ausência de crítica pode ser ao mesmo tempo desejada e temida. Teoricamente, o que Melman (n.d.) diz sobre um psicanalista não fazer discípulos na sua clínica psicanalítica pode parecer inatacável, mas não é tão difícil encontrar em alguns textos votos e suposições de assujeitamento dos futuros analistas aos mestres psicanalistas e às suas teorias. Alguns textos sobre a formação de psicanalistas fazem referências explícitas aos "candidatos" como objeto de um processo de formação um tanto infantilizante. Quando clamam por métodos mais ativos ou quando se preocupam com influências negativas que outros psicanalistas ou outros textos possam exercer sobre um candidato, parecem assumir que ele é alguém que está sendo "educado" para ser um psicanalista.

Em outros textos, há, sem dúvi$\mathrm{da}$, mais cautela em assumir uma posição semelhante. Se, por um lado, Lacan chega a opor ensino e saber, não se pode dizer que seja uma saída lacaniana abrir mão de qualquer ensino da teoria psicanalítica, como ele mesmo não fez. Aplicando o mesmo crivo teórico que a psicanálise aplica à educação, pode-se dizer que um psicanalista, ao trabalhar no ensino teórico de outros ou futuros psicanalistas, está colocando aí o seu desejo, não o de analista, mas talvez o de formador de analistas. Se o universo da teoria psicanalítica comporta tantas orientações teóricas diferentes, não é tão arbitrário quanto qualquer decisão de um educador que um psicanalista decida trabalhar na formação de acordo com uma orientação teórica particular? A partir do que Lajonquière (1999) e Melman (1999) expõem, talvez falte a algumas empreitadas de formação de analistas assumir o desejo, arbitrário como qualquer outro, de quem se propõe a ensinar a teoria psicanalítica. Kupfer (1990) menciona que professores que estudam a teoria psicanalítica têm para com ela a mesma atitude das crianças em relação ao que os professores lhes tentam ensinar, e Kupfer (2001) estabelece uma relação interessante entre o que Freud diz sobre educação e sua posição primeiro como discípulo e depois como mestre. Além de perguntar como Bernfeld e outros sobre que psicanalistas são formados a partir de uma "educação" pré-psicanalítica nos seus métodos, talvez se devesse perguntar também quais as implicações de um discurso que visa formar, mas precisa ocultar o desejo de seu agente e da instituição que o sustenta. Não se repetiria aí a ilusão de Neill, tão criticada por Millot (1995)?

A crítica lacaniana de Cifali e Imbert (1999) parece aproximar-se, ainda que indiretamente, do que Dör (1994) e Laplanche (1975) propõem. Enquanto os últimos acreditam num ensino da teoria psicanalítica que pos- 
sa evitar a sujeição do aluno, as primeiras propõem uma identificação simbólica e não imaginária entre aluno e professor. Fora de uma captação imaginária, o aluno pode permanecer sujeito, desde que o professor abdique dos benefícios imaginários de sua função. Ainda que não se possam aproximar as duas posições como se fossem a mesma, fica redundante nelas que alguém que se proponha a ensinar a teoria psicanalítica deva renunciar a estratégias de sujeição ou de captação imaginária. Como qualquer professor, um psicanalista pode buscar formar discípulos a partir do seu ensino, mas, ao contrário da posição de analisante, que é intrínseca a quem ensina, a do professor não é. Nem o ensino da teoria psicanalítica precisa ser assujeitante e formador de discípulos, nem a própria teoria precisa ser ignorada por futuros psicanalistas; contudo, quem se proponha a ensiná-la deverá se deparar de alguma forma com a sua posição de sujeito dividido, enquanto quem se propõe a ensinar a teoria psicanalítica e, como Valabrega (1983) já alertava, apenas criticar o ensino da teoria, não torna quem está ensinando imune ao que criticou.

A aceitação, proposta por Dör, de uma teoria psicanalítica que não ignore a indeterminação da transferência e de um ensino compatível com essa teoria parece uma alternativa na qual não é necessário recalcar a necessidade de teorizar ou de ensinar tal teoria. As conseqüências desse ensino, como de qualquer outro, não são previsíveis nem se pode supor um controle por quem ensina do que é dito ou do seu efeito. Paradoxalmente, quem quer que se proponha a ensinar pode desejar que a partir de seu ensino produzam-se novidades; que os discípulos possam aprender com ele algo que ele mesmo não saiba.

Finalmente, segundo Quinet (1992), o sujeito dividido que ensina deve colocar a teoria no lugar de significantes-mestres com o estatuto de enigmas a serem decifrados. Assim, uma alternativa possível para o necessário ensino da teoria psicanalítica parece relacionada diretamente à posição não assujeitante de quem ensina e ao lugar de um saber enigmático, mas passível de ser criticado da teoria psicanalítica.

\footnotetext{
Abstract

BETWEEN THE NECESSARY AND THE IMPOSSIBLE: THE PSYCHOANALYTICAL THEORY TEACHING IN THE PSYCHOANALYTICAL FORMATION

The psychoanalytical theory, even though between reinvention and repetition, is still part of the psychoanalytical formation and its teaching is required by many psychoanalytical institutions. The theory may avoid the psychoanalysis transmission to be reduced to transmitting powers, but its teaching may lead to subjection. The psychoanalytical theoretical framework applied to educational processes allow the identification here of
} 
disciples formation and, among those who teach, the not so spoken desire of future analysts that don't resist to theory. A psychoanalysis compatible teaching should refrain from subjection strategies and be open to the unconscious effects.

Index terms: psychoanalytical theory; psychoanalysis transmission; psychoanalysis teaching; psychoanalyst formation

\section{Resumen}

ENTRE EL NECESARIO Y EL IMPOSIBLE: LA ENSEÑ ANZ A DE LA TEORIA PSICO AN ALITICA EN LA FORMACIÓN PSICOANALÍTICA La teoría psicoanalítica, mismo que se quede entre la reinvención y la repetición, es parte de la formación analítica y su enseñanza es exigida por varias instituciones psicoanalíticas. $\mathrm{La}$ teoría puede evitar que la transmisión del psicoanálisis sea reducida a pasar poderes, pero su enseñanza puede ser sujetadora. El cuadro teórico psicoanalítico aplicado a los procesos educativos permite aqui identificar la formación de discípulos y, entre quien enseña, el deseo no asumido de futuros psicoanalistas que no resistan a la teoría. Una enseñanza compatible con el psicoanálisis debería abdicar de estrategias de sujeción y ser permeable a los efectos del inconsciente.

Palabras clave: teoría psicoanalitica; transmisión del psicoanálisis; enseñanza del psicoanálisis; formación del analista

\section{REFERÊNCIAS BIBLIOGRÁFICAS}

Aflalo, A. (1992). Escola: clínica e ensino. In J. Forbes (Org.), $A$ escola de Lacan: $A$ formação do psicanalista e a transmissão da psicanálise (pp. 21-26). Campinas, SP: Papirus.

Birman, J. (1991). Freud e a interpretação psicanalítica. Rio de Janeiro: Dumará.

(1994). Psicanálise, ciência e cultura. Rio de Janeiro: Zahar.

(1996). Por uma estilistica da existência. São Paulo: Editora 34.

Caon, J. L. (1994). O pesquisador psicanalítico e a situação psicanalítica da pesquisa. Psicologia: Reflexão e Crítica, 7(1), 145-174.
(1999). O pesquisador psicanalítico e a pesquisa psicanalítica. In J. T. Machado (Org.), Filosofia e psicanálise (pp. 35-74). Porto Alegre, RS: EDIPUC-RS.

Chemama, R., \& Vandermersch B. (1998). Dictionnaire de la psychanalyse. Paris: Larousse.

Cifali, M. \& Imbert, F. (1999). Freud e a pedagogia. (M. S. Gonçalves \& A. U. Sobral, trad.). São Paulo: Loyola.

Cottet, S. (1989). Freud e o desejo do psicanalista. (A. Roitman, trad.). Rio de Janeiro: Zahar.

Dör, J. (1993). A-cientificidade da psicanálise. (P. C. Ramos, trad.). Porto Alegre, RS: Artes Médicas.

(1994). Clinique psychanalytique. Paris: Denoël.

Ferreira, T. (1998). Freud e o ato do ensino. In E. M. T. Lopes (Org.), A psicanálise escuta a educação (pp. 107-149). Belo Horizonte, MG: Autêntica.

Freud, S. (1969a). Introdução a "The psycho-analytic method", de Pfister. In S. Freud, Edição standard brasileira das obras psicológicas completas de Sigmund Freud (J. Salomão trad.,Vol. 12, pp. 415-422). Rio de Janeiro: Imago. (Trabalho original publicado em 1913)

(1969b) A questão da análise leiga. In S. Freud, Edição standard brasileira das obras psicológicas completas de Sigmund Freud. (J. Salomão trad.,Vol. 20, pp. 212-284), Rio de Janeiro: Imago. (Trabalho original publicado em 1926)

(1969c). As resistências à psicanálise. In S. Freud, Edição standard brasileira das obras psicológicas completas de Sigmund Frend (J. Salomão trad.,Vol. 19, pp. 265-276). Rio de Janeiro: Imago. (Trabalho original publicado em 1925)

Gay, P. (1988) Freud: A life for our time. New York: Doubleday.

Kupfer, M. C. M. (1990). Desejo de saber. Tese de doutorado, Instituto de Psicologia Universidade de São Paulo, São Paulo. 
(2001). Freud e a educação: O mestre do impossivel. São Paulo: Scipione.

Lacan, J. (1992). O seminário, livro 17: O avesso da psicanálise, 1969-1970 (A. Roitman, trad.). Rio de Janeiro: Zahar.

(2003). Alocução sobre o ensino. In J. Lacan, Outros escritos (pp. 302-310).

Rio de Janeiro: Zahar.

Lajonquière L. de (1999). Infância e ilusão (psico)pedagógica. Petrópolis, RJ: Vozes.

Laplanche, J. (1975). Psychanalyse à l'université. Psychanalyse à l'Université, $1(1), 5-10$.

Lebovici, S. (1982). Sur la formation des psychanalystes. In S. Lebovici \& A. J. Solnit. La formation du psychanalyste (pp.17-43). Paris: PUF.

Melman, C. (n.d.). Le psychanalyste est un maître qui n'a pas de disciple. Texto recuperado em 23 set. 2004: http://209.236.238.226/articles/article. php?id_article $=00159$.

(1999). Sobre a educação das crianças. In C. Calligaris et al., Educa-se uma criança? (pp. 31-40). Porto Alegre, RS: Artes e Ofícios.

Millot, C. (1995). Freud antipedagogo. Rio de Janeiro: Zahar.

Quinet, A. (1992). A transmissão a partir de Lacan. In J. Forbes (Org.), A escola de Lacan: A formação do psicanalista e a transmissão da psicanálise (pp. 141-153). Campinas, SP: Papirus.

Roudinesco, E. (2000). Por que a psicanálise? Rio de Janeiro: Zahar.

Safouan, M. (1985). Jacques Lacan e a questão da formação dos analistas. Porto Alegre, RS: Artes Médicas.

Solnit, A. J. (1982). Réflexions sur la formation psychanalytique et la formation des psychanalystes. In S. Lebovici \& A. J. Solnit, La formation du psychanalyste (pp. 45-60). Paris: PUF.

Valabrega, J. P. (1983). A formação do psicanalista. São Paulo: Martins Fontes.

pppetry@ufrgs.br

Recebido em fevereiro/ 2006. Aceito em julbo/ 2006. 